\title{
Research on Subsidence Ageing of Soft Soil Roadbed Based on Original Position Monitor
}

\author{
Chenguang Jiang \\ College of Environmental and Civil Engineering, \\ Jiangnan University, \\ Jiangsu Wuxi 214122, P. R. China \\ E-mail: jiangcg999@126.com
}

\author{
Yong $\mathrm{He}$ \\ College of Civil Engineering, \\ Qingdao Agricultural University, \\ Shandong Qingdao 266109, P. R. China \\ E-mail: jiangcg999@163.com
}

\author{
Jianguo Peng \\ Department of Plan, \\ Communication Plan and Investigation and Design \\ Institute of Hunan Province, \\ Changsha 410011, P. R. China \\ E-mail: jiangcg999@sohu.com \\ Fengqin Wang \\ College of Environmental and Civil Engineering, \\ Jiangnan University, \\ Jiangsu Wuxi 214122, P. R. China \\ E-mail: jiangcg999@sina.com
}

\begin{abstract}
The stability of soft soil roadbed is a key factor for the properties and quality in motion of highway or railway. The process of stable soft soil roadbed has protracted nature. The stable of soft soil roadbed depend on the internal structure, composition, volume and external environment. Based on a vast amount of original position monitoring data, the problem of subsidence ageing of soft soil roadbed was studied as a whole. It summed up the regularity and features of subsidence ageing of soft soil roadbed. The mathematical model of subsidence ageing of soft soil roadbed has been given.
\end{abstract}

\begin{tabular}{lllr}
\multicolumn{1}{l}{ Keywords- } & Highway & Communication; & $\begin{array}{r}\text { Roadbed } \\
\text { Engineering; }\end{array}$ Soft Soil \\
Ageing;Experimental Model & Roadbed; & Subsidence;
\end{tabular}

\section{INTRODUCTION}

Soft clays, the glutinous soil sediment or river wash of sea facies, lagoon facies, delta facies, drowned-valley facies and limnic facies which are formed in the late quaternary, belongs to sediment of modern era, among which the silts and silt earth are the flabbiest. The soft soil is characterized by high moisture, high void ratio, low intensity, weak water permeability, low bearing capacity, low shear strength, high compressibility and high sensitiveness. Under the effect of load, the soft-soil groundwork's sedimentation deformation is great; its asymmetrical sedimentation is great; it takes longer time for the stabilization of sedimentation; and the dis-stability accidents occur easily.

Stabilization and sedimentation are the leading two restriction elements in the process of construction of speedways in soft-soil areas. Regarding the construction of speedways in soft-soil areas, the high filled road dyke on thick soft roadbeds is usually adopted, and when the project is completed, there are strict requirements on sedimentation. If there is a tight time limit for the construction of speedways, due to increase of expected pre-loading time and comparatively shortening of fill replacement time, the stability of roadbed is definitely exerted stricter requirements on[1]-[10] .

There must be accurate and reliable monitoring data for support if researchers want to study the subsidence ageing of soft soil roadbed. In order to obtain the monitoring data as accurate as possible, the research group and the author have made a systematic research on the scientific monitoring methods of soft soil roadbed subsidence, and summarized some efficient and high-accuracy monitoring methods.

According to the reliable and high-accuracy monitoring data of fixed point and normal position soft soil roadbed subsidence, researchers have made comparatively deep scientific and systematic analysis of the reason for soft soil roadbed subsidence in the surrounding Taihu Lake in recent years. On this basis, the initial conclusion on the basic law of subsidence ageing of soft soil roadbed in the surrounding Taihu Lake has been made out. The research group and the author have used the regression analysis theory and computer modeling technology when researchers made analysis on the basic law of subsidence ageing of soft soil roadbed in the surrounding Taihu Lake.

\section{MONITORING METHOD OF SUBSIDENCE AGEING OF SOFT SOIL ROADBED}

The observation result of sedimentation is gained through setting boundary line points, setting sedimentation boards underground and setting inclinometer casings. The boundary line points which should be determined in accordance with the conditions of groundwork and road embankment, are generally set at the road embankment section where the filling is relatively higher, including the two ends of filling section of soft-soil groundwork and structure objects. The points collocated should be parallel with midline; the position of points should reflect the sedimentation characteristics of this section; and generally, the boundary line points should be set symmetrically along the two sides of roadbed. The sedimentation boards are 
generally buried along the two sides of boundary, with their pedestals buried in the sand cushion, should be buried after the silt clearance and should be observed for the first time. Observation points of layered sedimentation should be set in the soils of different layers, following the direction of plumb line, with the number of points and depth determined according to distribution condition of delamination. In principle, a point is set in each layer of soil, with the lowest point set under the base and the deepest point exceeding the theoretical thickness of compressed layer or on the gravel or rock layers which are of low compressibility. The layered sedimentation instrument is made up of layered sedimentation tubes, magnetic rings, corrugation tubes and sedimentation instrument. Make holes in the middle of roadbed to the bearing layer, and install magnetic rings at corresponding depth according to geological condition; after descending the sedimentation tubes, seal holes with expansive soils to enable magnetic rings and stratum to make synchronous sedimentation; and use layered sedimentation instrument to measure the positions of each magnetic ring and calculate the sedimentation quantity of each layer respectively.

\section{EXPERIENCE FORMULA OF SUBSIDENCE AGEING OF SOFT SOIL ROADBED}

By use of computers, based on the relations between soft soil roadbed subsidence volume $\mathrm{h}$, compression modulus E, unit weight of soft soil roadbed $\rho$, thickness of soft soil roadbed $\mathrm{d}$, thickness of the soil above the hard rock $\mathrm{H}$ of several groups, together with regression analysis theory, the research group and the author draw a primary conclusion on the experienced mathematic formula on subsidence ageing of soft soil roadbed in the surrounding Taihu Lake, that is,

$$
h=0.4343 \times \rho \times d \times \ln (H+1) \times e^{(t / 97.3)} / E+0.0027
$$

In (1), h- soft soil roadbed subsidence volume $-\mathrm{m}, \rho-$ unit weight of soft soil roadbed $-\mathrm{N} / \mathrm{m} 3, \mathrm{~d}$ - thickness of soft soil roadbed-m, $\mathrm{H}$ - thickness of the soil above the hard rock-m, E-average compression modulus of the soil above the hard rock-Pa, e -the foundation of natural logarithm $(\mathrm{e}=2.718281828)$,t- the time span between the completion day of soft soil roadbed and a certain day of forecast-year, $\mathrm{t} \leqslant 30$.

If the depth of soil layers above the hard rock is Hi, and compression modulus is Ei then

$$
\begin{aligned}
& \mathrm{H}=\sum \mathrm{Hi} \\
& \mathrm{E}=\sum[\mathrm{Ei} \times \mathrm{Hi}] / \sum \mathrm{Hi}
\end{aligned}
$$

\section{DEMONSTRATIONS}

The Xi-cheng superhighway of Wuxi locates on the alluvial lake plain, the underground of which is extensively accumulated with the forth loose sediment soils which mainly include glutinous soils, powder soils and fine powder sands, with the total thickness of 100-190m and the total thickness at the motoring spot exceeding $80 \mathrm{~m}$.

For the purpose of scientific research, it is necessary to prospect for the roadbeds, making drilling to fetch soils with machines as the central tasks and combining static cone survey. In the process of drilling with machines, soil samples are fetched to make soil tests and standard penetration tests within the holes. The drilling on the spot is conducted with four G-1A type drilling machines, making omegatron whorl drilling as the main drilling approach, with diameter of opening holes of $135 \mathrm{~mm}$ and the diameter of bores of $110 \mathrm{~mm}$. In order to guarantee the quality of fetched soils and meet the requirement of standard penetration test, all the holes are filled with the upside separated by bushings and the drilling in conducted with slop protecting the wall. The soil catcher of take-up double-prick movable valve is adopted to fetch soil sample of the original state, using the method of impact sampling with soil catcher or static press method. The soil samples are sealed on the spot and delivered to the lab. The standard penetration test adopts the liberal weight drop which is automatically unhooked. Fifteen $\mathrm{cm}$ after the penetrator is stroked into the earth, the number of strikes of each $10 \mathrm{~cm}$ that is stroked into the earth is recorded, and the number of hammer strike that is used to strike $30 \mathrm{~cm}$ into the earth accumulatively is called the standard penetration strike number. The recorder is responsible for the differentiation, compilation and record of the drilling core, and responsible for the records of samples and the strike number of standard penetration test. The single bridge probe, adopted in the static cone survey, and penetrates continuously. After an interval of $10 \mathrm{~cm}$, the data is measured and read. The single bridge static cone survey adopts JC-H1 type of measurement instrument for static cone survey to record data, make tests on moisture, specific gravity and thickness to sample tests and conduct grain assaying to powder soil and sand soil. In order to acquire the mechanics index, concretion tests, direct shear tests and the unconsolidated-undrained triaxial shear tests are carried on.

The surrounding stratum of the Xi-cheng superhighway belongs to south of Yangtze stratum area, XiushuiQiantang River sub-area and Suzhou-Changxing community, and its bedrocks mainly show themselves in southern mountain areas. From old to new, there are stratums belonging to Palaeozoic era's Silurian period, Carboniferous period and Permian, Mesozoic's Triassic and Cretaceous, and Cenozoic's Tertiary and Quaternary. Except the stratum of Devonian that shows itself on the earth's surface and forms mountains, others all lie concealed under the stratum of the Quaternary.

The reconnaissance result shows that within the survey depth, the stratums are all alluvium of the Quaternary, belonging to the alleviation of middle and lower reaches of the Yangtze River. Within the maximum revealment depth of 20.5 meters, there are totally six layers of soil layer from top to the bottom, among which the (2), (3), (6) layers are divided into two sub-layers respectively. The character description of each rock and soil layer as well as the project characteristics are remarked as follows:

(1) Surface soil layer, brown and gray, is made up of rubbles and gravels on the top and gray and lark cohesive plain backfill in the bottom in the sections of villages, factories and roads; and it is the cultivation soil in the section of farmland. This soil layer, the thickness of which is generally $0.7-2.5 \mathrm{~m}$, is loose and of bad equality.

(2) -1 is powder claypan, and partially is clay, taking on the color of lark. It is in the state of plasticizing and stiffplastic, contains iron-manganese nodules and green and grey kaolin streaks and has not shaking and rocking 
reaction. It is sheeny, of high dry intensity and of high tenacity. The powder claypan, whose layer thickness is generally $4.1-4.6 \mathrm{~m}$, distributes partly. It belongs to the medium compactable soil and has good project characteristics.

(2)-2 is powder claypan, and partially is clay, taking on the color of lark. It is in the state of plasticizing and stiffplastic, contains iron-manganese nodules and green and grey kaolin streaks and has not shaking and rocking reaction. It is sheeny, of high dry intensity and of high tenacity. The powder claypan, whose layer thickness is generally $3.2-5.8 \mathrm{~m}$, is of no distribution at part of places. It belongs to the medium compactable soil and has good project characteristics.

(3) -1 is the powder soil layer, taking on the color of lark. It is in the slightly dense and mediumly dense state, containing a few glutinous soils, and is quite wet. It is of bedding structure, has rapid shaking and rocking reaction, has no sheen, is of low dry intensity and is of low tenacity. The powder soil layer, whose thickness is $0.0-3.6 \mathrm{~m}$, distributes at part of places. It belongs to medium compactable soil and has ecumenic project characteristics.

(3)-2 is powder clay containing powder soil, taking on the color of filemot - taupe with the bottom turning gray. It is mainly of plasticizing state and has bedding structure. Part of the bottom of this layer is mainly of powder soil. It has medium shaking and rocking reaction, slightly sheen, of medium dry intensity and of medium tenacity. This layer of soil, whose thickness is generally $0.0-5.2 \mathrm{~m}$, spreads in the full field. It belongs to medium compactable soil and has ecumenic project characteristics.

(4) is powder clay layer of soil, gray, taking on the state of soft plastic - flowing plastic, containing a few lamina of powder soils. It is of slightly bedding structure, of no shaking and rocking reaction, of slightly sheen, of medium dry intensity and of medium tenacity. This layer of soil, whose thickness is $0.0-2.5 \mathrm{~m}$, spreads in the full field. It belongs to medium and slightly high compactable soil and has relatively bad project characteristics.

(5) is powder soil layer, gray, taking on the state of slightly dense-mediumly dense, containing a small quantity of glutinous soils in the bottom, quite wet. It is of bedding structure, of rapid shaking and rocking reaction, of no sheen reaction, of low dry intensity and low tenacity. This layer of soil, whose thickness is generally $4.8 \mathrm{~m}$, spreads in the full field. It belongs to medium and slightly low compactable soil and has ecumenic project characteristics.

(6) -1 is powder clay layer, taking on the color of dark ashy green and gradually turning into yellow green. It is in the state of plasticizing-soft plastic, with slightly worse state on the top. It is of no shaking and rocking reaction, sheeny, of high dry intensity and medium tenacity. This layer of soil, whose thickness is $0.0-1.8 \mathrm{~m}$, distributes at part of places. It belongs to medium compactable soil and has ecumenic project characteristics.

(6)-2 is powder clay layer of soil and part of this layer is clay, taking on the color of dark ashy green and gradually turning into yellow green and then into ashy yellow. It is in the state of plasticizing-hard plastic, of no shaking and rocking reaction, of sheen, of high dry intensity and high tenacity. In the process of this reconnaissance, this layer hasn't been fully penetrated. It belongs to medium and slightly low compactable soil and has good project characteristics.

The geotechnical test results (part) of each soil layers refer to TABLE I, curve of static cone survey (part) refers to Fig .1 and section plane picture of project geology (part) refers to Fig .2.

According to reconnaissance result, comprehensively analyzing soil layer condition within the field and regional geological materials, researchers find out that the thickness of the coverage layer within the field is more than $50 \mathrm{~m}$, and the type of soil within the field is medium soft soil. According to wave velocity test result, the sort of the field is determined as the Grade III.

According to the drilling exposure, it is estimated that within 20 meters of prospecting depth of the field, the main layers that contain water include surface soil on the top of (1) layer which belongs to backwater-phreatic water type, powder soil on the middle and top of (3)-1 layer which belongs to feeble confined water, powder clay containing powder soil of the (3)-2 layer and powder soil of the (5) layer.

The type of ground water in the shallow part of the field belongs to phreatic water. In the process of reconnaissance, it is measured that the comparatively stable ground water in every holes is generally $0.60-$ $1.40 \mathrm{~m}$ apart from the earth's surface and the Yellow Sea Datum is $1.65---2.50$ meters.

Around the field, bad geological effects such as new active rupture structure and terra cracks haven't been discovered yet. According to regional geological materials and geological materials of surrounding projects, there are not bad geological phenomena, such as new active rupture structures and terra cracks and son on in the surrounding area of the Xi-cheng superhighway. And there are also not possible liquefacient soil layers within the field. The seismic fortification intensity of Wuxi areas is six degrees. According to historical records, earthquakes with magnitudes over five have never happened within the range of forty kilometers in recent one hundred odd years. Therefore, this field is stable.

As for the place that is twenty seven kilometers apart from the Xi-cheng superhighway, the relevant calculation parameter is $\rho=19012 \mathrm{~N} / \mathrm{m} 3, \mathrm{~d}=5.8 \mathrm{~m}, \mathrm{H}=87.6 \mathrm{~m}$, $\mathrm{E}=5.76 \mathrm{MPa}, \mathrm{t}=6$ years. According to formula (1), researchers can get the result is that $\mathrm{h}=0.7746 \mathrm{~m}$.. the actual total sedimentation quantity is $0.7721 \mathrm{~m}$.

Through plenty of checking computations to actual motoring data, researchers draw out the conclusion, that is, the average relative error of the experience formula of final sedimentation quantity of soft-soil roadbed in Yangtze River Delta area given by this article is $11.4 \%$, and its maximum relative error is $19.1 \%$.

The forecast effect of the experienced mathematic formula on subsidence ageing of soft soil roadbed at $\mathrm{Xi}$ cheng superhighway is shown in TABLE II.

In TABLE II, the relative error $\mathrm{K}$ is

$\mathrm{K}=\{|\mathrm{H}-\mathrm{h}| / \mathrm{H}\} \times 100$

It is seen from TABLE II that the experienced mathematic formula on subsidence ageing of soft soil roadbed is highly precise. 
Fig .3 shows the curve shape and the coincidence between the forecast result and actual data of subsidence ageing of soft soil roadbed forecast model.

\section{CONCLUSION}

The problem on subsidence ageing of soft soil roadbed is a complex scientific matter, needs the support of numerous, continuous, highly reliable and multiple-subject basic Field surveying data, requires scientists of the world working hard, persistently and continuously, also the assistance of basic theories and acknowledge on many subjects.

The soft soil roadbed subsidence features on special internal rules and certain recoverability. It follows the basic rules from fall, recovery (or partial recovery), fall again, recovery again (or partial recovery).

The opinions and the results in this article are based on special region, its reliability and validity requires the verification in a larger scope, and its errors on limitation and representation are unavoidable. Researchers hope your comments and corrections on the false and improper; also, the author hopes this article is able to help to enlighten the research on soft soil roadbed subsidence.

\section{ACKNOWLEDGMENT}

The research project discussed in this paper has been funded by the National Natural Science Fund of China (No.79160173) and Southern Yangtze University 211
Construction Fund (No.2004012) . Sincere gratitude is presented to them.

\section{REFERENCES}

[1] Asaoka A. Observational procedure of settlement prediction [J]. Soils and Foundations, 1978, 18 (4) : 30-34.

[2] Parkinson W. Bradford, Spilker J., Enge P.Global Positioning System: Theory and Applications [M]. AIAA Washington DC. 1996

[3] Hehai University, The Expressway Co Ltd of Jiangsu. The soft clay project handbook of the traffic construction [M]. Beijing : China Communications Press, 2001.

[4] Liu Yu-zhuo. The treatment of highway soft clay roadbed[M]. Beijing : China Communications Press, 2002.

[5] Chang Bao-ping. Improvement of settlement prediction for the embankment on soft soil $[\mathrm{J}]$. China Journal of Highway and Transport, 1993, 8 (3) : 5-9.

[6] Qi Huan. The model method of mathematics [M]. Wuhan : Huazhong University of Technology Press, 1996.

[7] Chen-guang JIANG. Mathematical simulation and observation of ground subsidence basin in coal mining area[J].Transactions of Nonferrous Metal Society of China,2005,(S.1):17-19

[8] Chen-guang JIANG. Monitoring and Analysis of Recoverable Subsidence Threshold Value of Earth's Surface[J].Proceedings of the Seventh International Symposium on Land Subsidence,361-369

[9] Chen-guang JIANG. know conception on earth subsidence in mining area $[\mathrm{J}]$. Chinese Journal of Rock Mechanics and Engineering,2003 (1) : 162-165

[10] Chen-guang JIANG,et al. Wuxi City Geology[M]. Hohai University Press, Nanjing,2014.

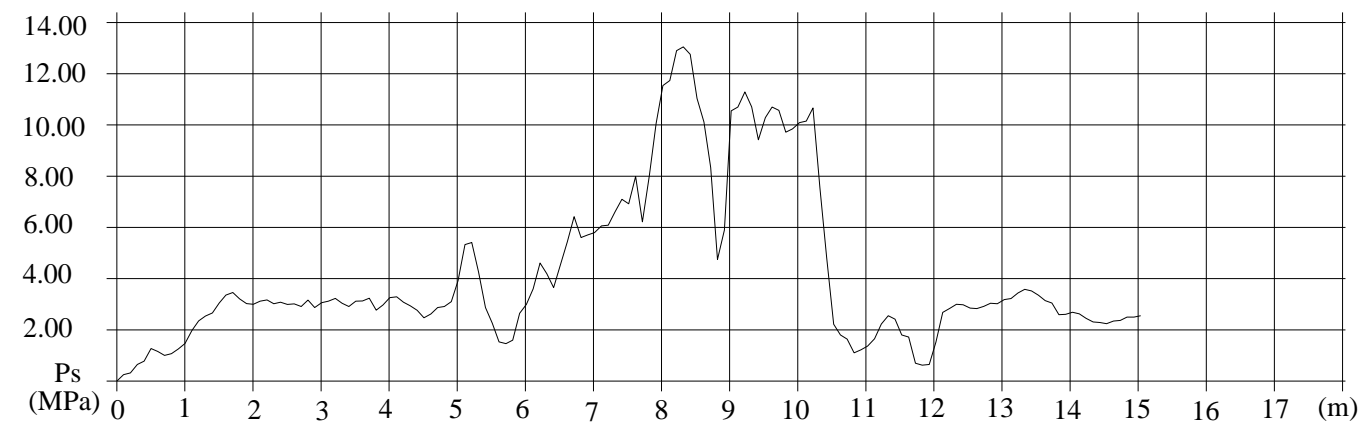

Figure 1. Curve of static cone survey 


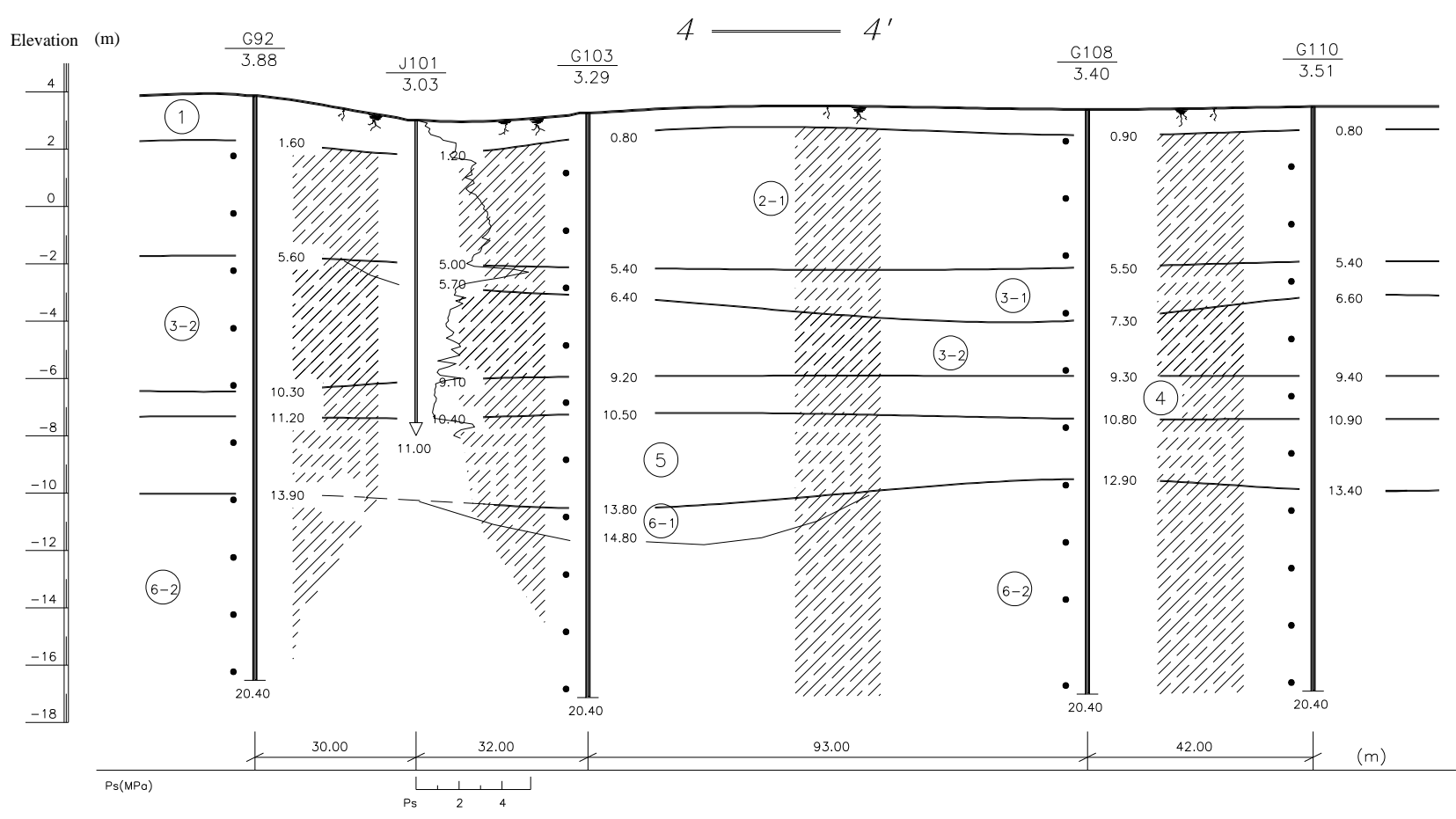

Figure 2. Section plane picture of project geology

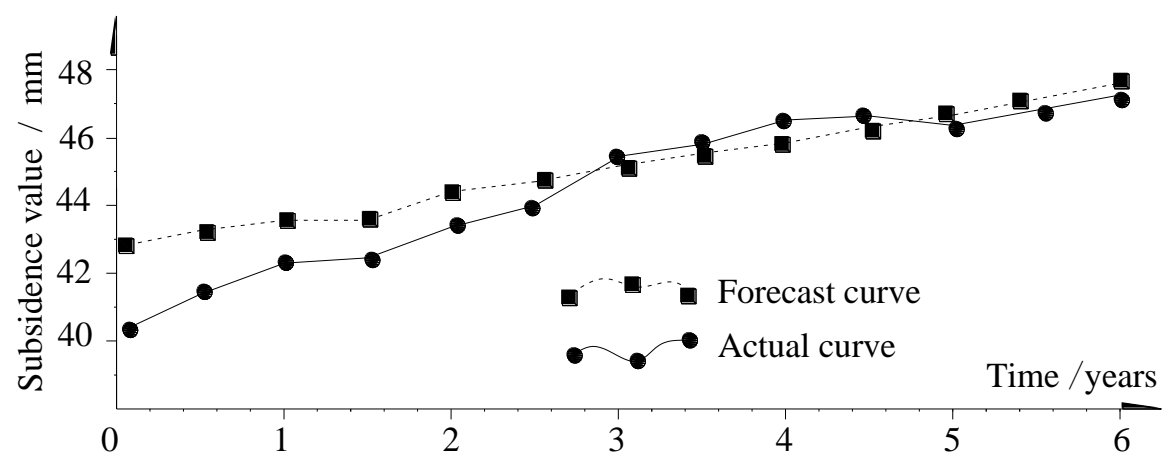

Figure 3. Curve of subsidence ageing of soft soil roadbed forecast model and actual subsidence curve

TABLE I. GEOTECHNICAL TEST RESULT

\begin{tabular}{|c|c|c|c|c|c|c|c|c|c|c|c|c|}
\hline No. & $\begin{array}{c}\text { Soil } \\
\text { names }\end{array}$ & $\begin{array}{c}\text { Sampling } \\
\text { depth } \\
\text { (m) }\end{array}$ & $\begin{array}{c}\text { Natural } \\
\text { water } \\
\text { content } \\
\text { W } \\
\%\end{array}$ & $\begin{array}{c}\text { Gravity } \\
\text { dense } \\
\mathrm{r} \\
\mathrm{kN} / \mathrm{m}^{3}\end{array}$ & $\begin{array}{c}\text { Dry } \\
\text { density } \\
\text { rd } \\
\mathrm{kN} / \mathrm{m}^{3}\end{array}$ & $\begin{array}{l}A . \\
B .\end{array}$ & $\begin{array}{l}\text { Specific } \\
\text { gravity } \\
\text { Gs }\end{array}$ & $\begin{array}{c}\text { Porosity } \\
\mathrm{n} \\
\%\end{array}$ & $\begin{array}{c}\text { C. Liquid } \\
\text { D. limit } \\
\text { WL }\end{array}$ & $\begin{array}{c}\text { E. Plastic } \\
\text { F. limit } \\
\text { WP }\end{array}$ & $\begin{array}{l}\text { Compress } \\
\text { modulus } \\
\text { Es } \\
\mathrm{MPa}\end{array}$ & $\begin{array}{l}\text { Angle } \\
\text { of } \\
\text { internal } \\
\text { friction } \\
\phi^{\circ}\end{array}$ \\
\hline $1-1$ & clays & 2.1 & 23.6 & 19.50 & 15.78 & & 2.73 & 42.2 & 38.6 & 20.2 & 7.22 & 9.0 \\
\hline $1-2$ & clays & 4.1 & 25.1 & 19.60 & 15.67 & & 2.73 & 42.6 & 39.8 & 20.9 & 8.98 & 10.0 \\
\hline $1-3$ & $\begin{array}{c}\text { Powder } \\
\text { clay }\end{array}$ & 6.1 & 21.8 & 19.90 & 16.34 & & 2.72 & 39.9 & 34.0 & 17.5 & 7.88 & 16.0 \\
\hline $1-4$ & $\begin{array}{c}\text { Powder } \\
\text { clay }\end{array}$ & 8.1 & 28.1 & 19.20 & 14.99 & & 2.71 & 44.7 & 35.8 & 22.9 & 8.06 & 15.0 \\
\hline $1-5$ & $\begin{array}{c}\text { Powder } \\
\text { clay }\end{array}$ & 10.1 & 31.8 & 18.90 & 14.34 & & 2.71 & 47.1 & 35.4 & 21.7 & 4.85 & 9.0 \\
\hline $1-6$ & $\begin{array}{c}\text { Powder } \\
\text { soil }\end{array}$ & 12.1 & 37.1 & 18.30 & 13.35 & & 2.69 & 50.4 & & & 5.14 & 20.0 \\
\hline
\end{tabular}




\begin{tabular}{|c|c|c|c|c|c|c|c|c|c|c|c|}
\hline $1-8$ & $\begin{array}{c}\text { clay } \\
\text { powder } \\
\text { clay }\end{array}$ & 16.1 & 23.6 & 19.50 & 15.78 & 2.72 & 42.0 & 35.6 & 20.1 & 10.49 & 18.0 \\
\hline $1-9$ & clays & 18.1 & 22.0 & 19.90 & 16.31 & 2.73 & 40.3 & 37.7 & 18.8 & 9.07 & 12.0 \\
\hline
\end{tabular}

TABLE II. COMPARISON BETWEEN THE FORECAST VALUE AND ACTUAL VALUE

\begin{tabular}{|c|c|c|c|c|c|c|c|}
\hline Time & Actual & Forecast & Relative & Time & Actual & Forecast & Relative \\
\hline Span & Value & Value & Error & Span & Value & Value & Error \\
\hline $\mathrm{t}$ & $\mathrm{H}$ & $\mathrm{h}$ & K & $\mathrm{t}$ & $\mathrm{H}$ & $\mathrm{h}$ & K \\
\hline years & $\mathrm{mm}$ & $\mathrm{mm}$ & $\%$ & years & $\mathrm{mm}$ & $\mathrm{mm}$ & $\%$ \\
\hline $1 / 12$ & 41.9 & 43.6 & 4.1 & 3 & 45.0 & 44.8 & 0.4 \\
\hline 0.5 & 42.6 & 43.8 & 2.8 & 3.5 & 45.3 & 45.1 & 0.4 \\
\hline 1 & 43.1 & 44.0 & 2.1 & 4 & 45.7 & 45.3 & 0.9 \\
\hline 1.5 & 43.4 & 44.2 & 1.8 & 4.5 & 45.7 & 45.5 & 0.4 \\
\hline 2 & 43.7 & 44.4 & 1.6 & 5 & 45.4 & 45.7 & 0.7 \\
\hline 2.5 & 44.1 & 44.6 & 1.1 & 6 & 46.0 & 46.2 & 0.4 \\
\hline
\end{tabular}

